\title{
Low-power cryocooler survey
}

\author{
H.J.M. ter Brake *, G.F.M. Wiegerinck \\ Low-Temperature Division, Department of Applied Physics, Center for Interfacing Low-Temperature Electronics and Coolers, \\ University of Twente, P.O. Box 217, 7500 AE Enschede, The Netherlands
}

Received 8 August 2002; accepted 4 October 2002

\begin{abstract}
A cryocooler survey has been performed on data of 235 cryocoolers, with cooling powers below some tens of watts and operating between 4 and $120 \mathrm{~K}$. The state-of-the-art is discussed and trends are investigated on cooling performance, mass and size, cost, lifetime and reliability. The data were compared with earlier surveys to explore historical trends. Improvements in cooling performance were mainly in $80 \mathrm{~K}$ cryocoolers, an increase in efficiency by about a factor of 5 . Coolers did not reduce in size significantly. Main reduction was in $80 \mathrm{~K}$ coolers because of the higher efficiency. In the survey, cost is related to input power, cooling power and operating temperature. Cost development is considered and related to learning curves. Since the mid-90s, the lifetime of Stirling-type cryocoolers has increased by one order of magnitude from typically 0.5 to 5 years or more. The confusion that exists on the term "reliability" is discussed.
\end{abstract}

(C) 2003 Elsevier Science Ltd. All rights reserved.

Keywords: Gifford-McMahon (E); Stirling (E); Pulse tube (E); Joule-Thomson coolers (E); Brayton cycle (E)

\section{Introduction}

In the last four decades, cryocoolers were developed for an increasing number of applications in a slowly, yet steadily, increasing market. In the early days, applications were limited to cryopumping and cooling of infrared sensors. For cryopumping, Gifford-McMahon cryocoolers with a few watts of cooling power at $20 \mathrm{~K}$ were usually used, whereas for cooling IR sensors, Stirling coolers with about $1 \mathrm{~W}$ at $80 \mathrm{~K}$ were applied. Other applications came up, each with its own set of requirements. Thermal radiation shield cooling in MRI systems needed even more powerful GM coolers, establishing helium-refill times of more than a year. As another example, superconducting devices did not require a significant cooling power but often had extreme other demands: on interference as in the case of SQUIDs or on reliability as in the case of HTS filters in telecom systems.

Stimulated by this growing variety of applications, coolers were improved and new cooler types were in-

\footnotetext{
${ }^{*}$ Corresponding author. Tel.: +31-53-489-4349; fax: +31-53-4891099.

E-mail address: h.j.m.terbrake@tn.utwente.nl (H.J.M. ter Brake).
}

vented and developed. An important improvement was the application of magnetic-phase-transition materials in the regenerators of two-stage mechanical coolers, thus establishing cooling of up to $1 \mathrm{~W}$ at $4 \mathrm{~K}$. A typical example of a new type of cooler is the pulse-tube cooler that was invented in 1963 [1], but found its way to "real" applications after the introduction of the so-called orifice in 1984 [2]. After having realized an acceptable performance in terms of efficiency and attainable temperature, in the last decade, the main cooler improvements were established on reliability, cost and size. Reliability and a long lifetime were requirements originally put forward by space applications but later on also demanded by commercial HTS applications. The largest improvement here is the incorporation of clearance seals and flexure bearings. This technology lifted the specified lifetime of commercial coolers from typically 0.5 year to potentially more than 5 years. Another challenge that manufacturers were, and still are, facing is to realize these highly reliable coolers at a sufficiently low cost. Cooler manufacturers are continuously improving the design of the coolers and manufacturing them with cost being the main driver. More recently, attention is being paid to the size of the cooler. Since electronic devices get smaller and smaller in terms of size and dissipation, there is a need for extremely small coolers 
(with dimensions of centimeters) with small cold heads (order of $\mathrm{mm}$ ) and low cooling powers (order of $\mathrm{mWs}$ ). Extreme miniaturization is possible by using micromechanical techniques. For more detailed information on coolers and cooler developments, the reader is referred to the literature [3-5]. In this process of developing cryocooler technology parallel to market potentials, from time to time cryocooler surveys were presented. Usually, a cooler database was presented in combination with some trend graphs and a more or less detailed discussion on those.

In 1969, two surveys were published. Daunt and Goree presented a survey of 39 coolers, 19 suppliers, in operating temperature ranges 7-12 K, 12-35 K, and 35$80 \mathrm{~K}$ in which they included trend lines of an earlier survey [6]. Strobridge presented a survey [7] that was updated in 1974 [8] on 144 coolers that were considered in the temperature ranges $1.8-9 \mathrm{~K}, 10-30 \mathrm{~K}$, and $30-90$ K. In 1970, a database on relatively large-power coolers and liquefiers was presented by Crawford (input power typically above $10 \mathrm{~kW}, 65$ coolers, 10 suppliers) [9]. The 1969 survey of Daunt and Goree was updated by Smith et al. in 1984 [10]. In this update, focus was on small coolers in the temperature range $4-80 \mathrm{~K}$. A total of 69 commercially available cryocoolers was presented in the database, supplied by 22 manufacturers. To our knowledge, the most recent cooler survey was prepared for the U.S. Air Force Research Laboratory in 2000 [11]. However, this survey was on a limited number of space coolers only. A recent survey with a much wider

Table 1

Parameters in the CILTEC 2002 Cryocooler database

\begin{tabular}{l} 
Supplier \\
Cooler model \\
Cycle type (e.g. Stirling) \\
Compressor type (e.g. rotary) \\
Expander type (e.g. resonant displacer) \\
Configuration (split/integrated) \\
Operation (continuous or periodic) \\
Number of stages \\
Compressor cooling \\
Status of development \\
Commercial availability \\
Cost: 1 unit, 100 units \\
No load coldest stage temperature \\
Cooling power @ $4 \mathrm{~K}, 10 \mathrm{~K}, 20 \mathrm{~K}, 40 \mathrm{~K}, 80 \mathrm{~K}$ \\
Cooling power and temperature at second stage \\
Heat rejection temperature \\
Electrical input power (incl. electronics) \\
Cooling-power data from measurement, simulation, or design goal \\
\# cooler units \\
Cumulative \# operating hours \\
\# failures \\
Lifetime \\
Maintenance interval \\
Electronics (integrated or separate) \\
Dimensions (of compressor, expander, and electronics) \\
Mass (of compressor, expander, and electronics) \\
Applications \\
\hline
\end{tabular}

coverage was prepared on CD by Nichols Research, sponsored by the Naval Research Laboratory (NRL) [12]. This survey was discussed at the International Cryocooler Conference in 1998 [13]. Although the database is a very rich and user-friendly source of cooler information (154 coolers of 36 suppliers), it appeared difficult to transform the data into useful trend lines. The graphs presented in Ref. [13] contain too much scatter in this respect. Therefore, we decided to generate a new cryocooler database and again to investigate the trends. The objectives were twofold. First, we wanted to put up-to-date cryocooler specifications in a database, and second, we aimed to derive trend lines not only in terms of e.g. performance versus operating temperature, but also in historical perspective. These trends can be used as input in roadmap studies.

In our survey, we started with the data from the above-mentioned NRL-Nichols survey and added any further information that we could find on the Internet or which we had available in our research group. All suppliers were approached with the specific data that we

Table 2

List of suppliers in database

\begin{tabular}{|c|c|}
\hline Advanced Research Systems & www.arscryo.com \\
\hline AEG Infrarot-Module (AIM-IR) & www.aim-ir.com \\
\hline Air Liquide & www.airliquide.com \\
\hline Aisin Seiki & www.aisin.co.jp \\
\hline SHI-APD Cryogenics & www.apdcryogenics.com \\
\hline Astrium & www.astrium-space.com \\
\hline CMC Electronics Cincinnati & www.cmccinci.com \\
\hline Creare & www.creare.com \\
\hline Cryomech & www.cryomech.com \\
\hline CTI Cryogenics & www.helixtechnology.com \\
\hline DAIKIN Industries & www.daikin.co.jp \\
\hline Denso Corporation (Cryodevice) & www.denso.co.jp \\
\hline DRS Technologies $^{\mathrm{a}}$ & www.drs.com \\
\hline FLIR Systems & www.flir.com \\
\hline IGC Polycold Systems & www.polycold.com \\
\hline ILK Dresden & www.ilkdresden.de \\
\hline Litton Life Support ${ }^{\mathrm{a}}$ & www.littonls.com \\
\hline Leybold Vacuum ${ }^{\mathrm{a}}$ & www.leyboldvac.de \\
\hline Mesoscopic Devices $^{\mathrm{a}}$ & www.mesoscopic.com \\
\hline MMR Technologies & www.mmr.com \\
\hline Raytheon Electronic Systems & www.raytheon.com \\
\hline Raytheon Infrared Operations & www.raytheon.com \\
\hline Ricor $^{\mathrm{a}}$ & www.ricor.com \\
\hline $\begin{array}{l}\text { Stirling Cryogenics \& Refrigeration } \\
\text { (SCR) }\end{array}$ & www.stirling.nl \\
\hline Stirling Technology Company & www.stirlingtech.com \\
\hline Sumitomo Heavy Industries & www.shi.co.jp \\
\hline SR \& DB/Orbita & - \\
\hline $\begin{array}{l}\text { Superconductor Technologies Inc. } \\
\text { (STI) }\end{array}$ & www.suptech.com \\
\hline Sunpower & www.sunpower.com \\
\hline $\begin{array}{l}\text { Technical Institute of Physics and } \\
\text { Chemistry, Chinese Academy of } \\
\text { Sciences }\end{array}$ & - \\
\hline Thales Cryogenics & www.thales-cryogenics.com \\
\hline $\mathrm{TRW}^{\mathrm{a}}$ & www.trw.com \\
\hline
\end{tabular}

${ }^{a}$ Data not corrected by supplier. 
had on their coolers, and they were asked to update this. Thanks to the effectiveness of modern electronic communication and the cooperation of suppliers, we have compiled a database of 235 cooler configurations from 32 suppliers. We explicitly tried to get data for the operating temperatures $4,10,20,40$, and $80 \mathrm{~K}$. Although a
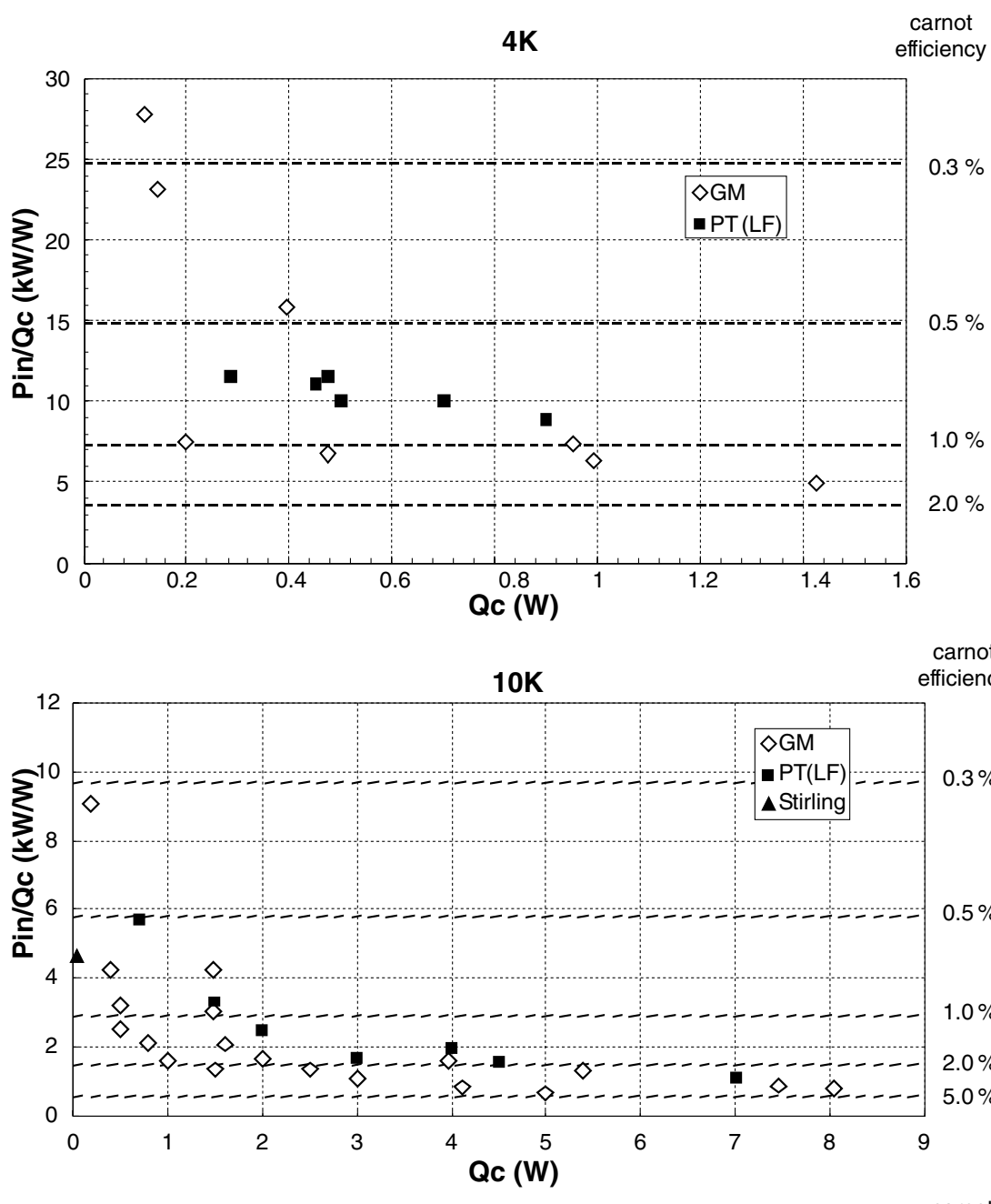

carnot

efficiency

$0.3 \%$

$0.5 \%$

$1.0 \%$

$2.0 \%$

$5.0 \%$

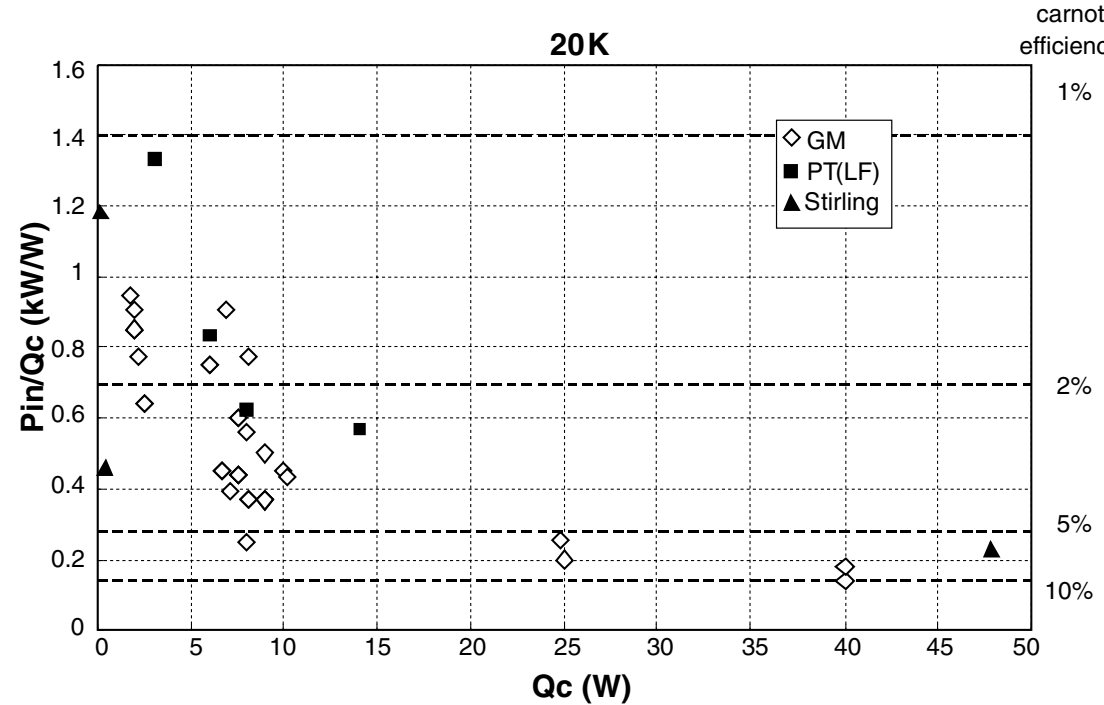

Fig. 1. Specific power versus cooling power at five operating temperatures. (Note: At $80 \mathrm{~K}$ the specific power is expressed in W/W, at all other temperatures in $\mathrm{kW} / \mathrm{W}$.) 

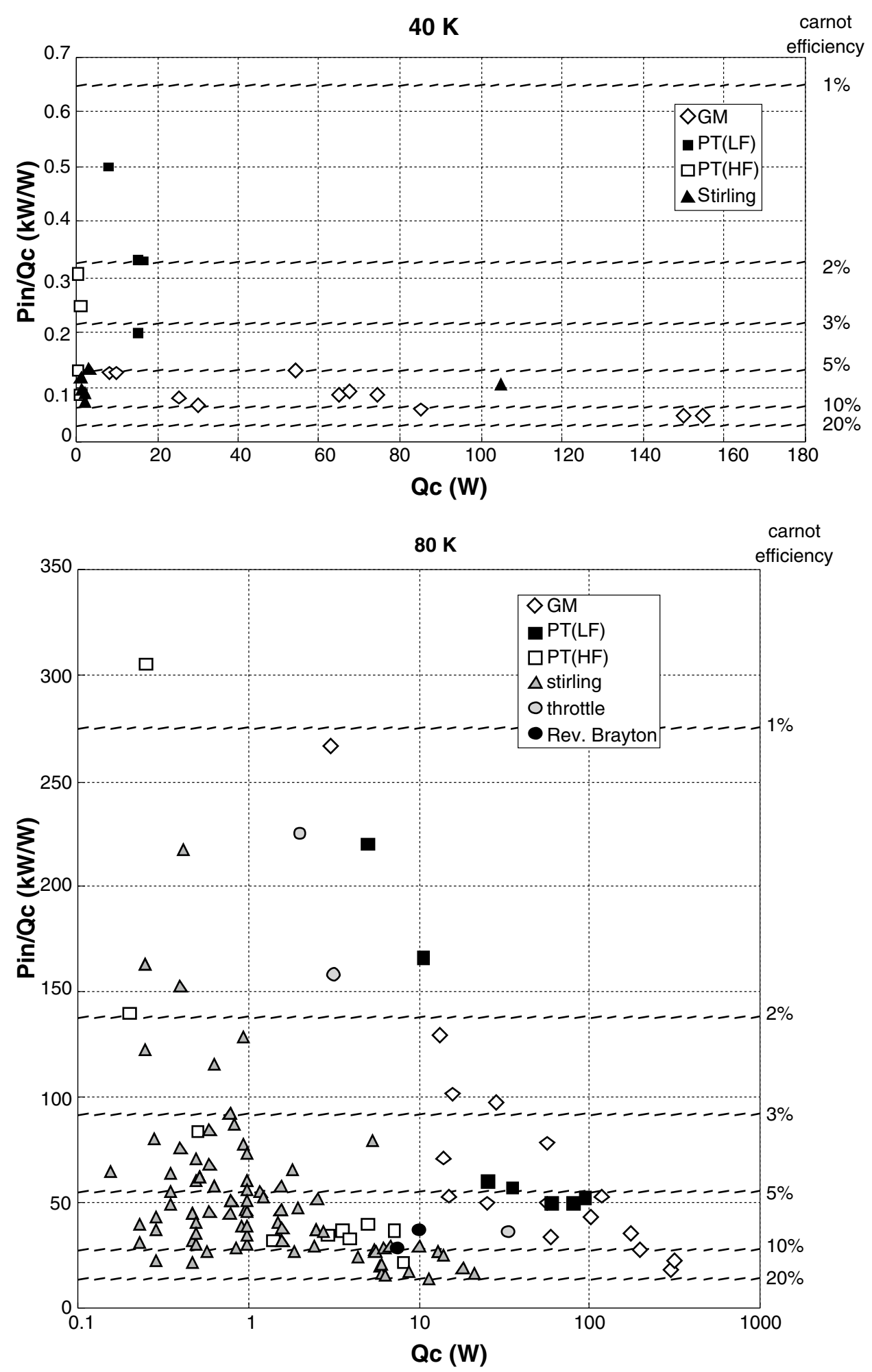

Fig. 1 (continued)

few other coolers are included, we primarily focused on cryocoolers with cooling powers below some tens of watts. The cooler parameters that are considered in the database are given in Table 1. A list of the suppliers who participated in the survey is given in Table 2. This cryocoolers survey was performed at the "Center for Interfacing Low-Temperature Electronics and Coolers" (CILTEC) at the University of Twente [14]. In this paper, a selected set of parameters is discussed and trends are considered in their mutual relation. The rel- 
evant parameters in this respect are cooling performance (involving cooling power, input power, and operating temperature), mass (and volume), cost and lifetime. Six cooler types are distinguished in this study: Gifford-McMahon (GM), Stirling, Stirling-type or high-frequency pulse tube, GM-type or low-frequency pulse tube, throttle type (i.e. fluid expansion over a flow restriction), and reversed Brayton (expansion over a turbine) [3-5].

\section{Cooling performance}

Various ways of expressing the performance of a cryocooler exist and the definitions are confusing in this respect. A cooler lifts heat $Q_{\mathrm{C}}$ from a cold reservoir at temperature $T_{\mathrm{C}}$ at the expense of an input power $P_{\text {in }}$ at a heat-sink temperature $T_{\mathrm{H}}$. Following common practice in thermodynamics, we define the coefficient of performance $(\mathrm{COP})$ as

$\mathrm{COP}=Q_{\mathrm{C}} / P_{\text {in }}$

Often also the specific power is used defined as $\mathrm{COP}^{-1}$. The efficiency of a cooler is usually quoted as the ratio of the actual cooler COP to that of the ideal Carnot cycle:

$\eta=\mathrm{COP}_{\text {cooler }} / \mathrm{COP}_{\text {Carnot }}$

with

$\mathrm{COP}_{\text {Carnot }}=T_{\mathrm{C}} /\left(T_{\mathrm{H}}-T_{\mathrm{C}}\right)$

Because "efficiency" is often mixed with "COP", it is best to express the efficiency in percent Carnot.

The non-ideal performance of a cooler is caused by various loss mechanisms such as conductive heat losses along the cooler and shuttle heat losses inside it. Relative to the required heat lift $Q_{\mathrm{C}}$, these losses increase as the operating temperature is lowered and also when $Q_{\mathrm{C}}$ gets smaller. As a result, one may expect the percent Carnot efficiency to be smaller at lower operating temperatures. Furthermore, at a given operating temperature, one may expect the efficiency to improve as $Q_{\mathrm{C}}$ is increased.

In order to compare the different coolers in our database in a well-founded manner, we transformed all data to the operating temperatures $4,10,20,40,80 \mathrm{~K}$, and to a heat-sink temperature of $300 \mathrm{~K}$. Some suppliers gave specifications at slightly different temperatures such as 4.2 or $77 \mathrm{~K}$, or a heat sink at $290 \mathrm{~K}$. These data points were corrected via the Carnot COP as given by Eq. (3). Data that deviated too much, e.g. $60 \mathrm{~K}$ performance, was not included at this point of the study. The resulting specific powers versus cooling powers are depicted in Fig. 1. As expected, a lower operating temperature gives a lower performance and at high values of $Q_{\mathrm{C}}$ the specific power tends to level off. At the lower temperatures, there is no dramatic difference between the various
Table 3

Maximum $\eta$ versus operating temperature

\begin{tabular}{lcl}
\hline$T_{\mathrm{H}}(\mathrm{K})$ & $Q_{\mathrm{C}}(\mathrm{W})$ & $\eta_{\max }(\%)$ \\
\hline 4 & $>1$ & $1-2$ \\
10 & $>5$ & $2-5$ \\
20 & $>25$ & $5-10$ \\
40 & $>80$ & $10-20$ \\
80 & $>10^{\mathrm{a}}$ & $10-20$ \\
\hline${ }^{\mathrm{a}}$ Valid for Stirling coolers and high-frequency pulse-tube coolers.
\end{tabular}

Other coolers have a threshold of about $80 \mathrm{~W}$.

cooler types in terms of efficiency. At $80 \mathrm{~K}$, however, a distinct difference shows up between two categories of coolers. On the one hand, coolers for the $1 \mathrm{~W}$ range (Stirling and Stirling-type pulse-tube coolers) and on the other hand, coolers for the $10 \mathrm{~W}$ and above range (GM and GM-type pulse-tube coolers). Below about $10 \mathrm{~W}$, the former category has a much better performance than the latter. This higher performance in the $80 \mathrm{~K}$ range was probably driven by the demands from infrared community and by the requirements for the HTS microwave filter systems that are being proposed for use in wireless communication base stations. The results of Fig. 1 are summarized in Table 3.

For a comparison with earlier surveys, the database was used without correcting the operating temperature. The correction for deviations in heat-sink temperature, however, was maintained. Regardless of the heat lift, the specific power of "our" coolers is depicted as a function of the operating temperature in Fig. 2a. Here, only the "low-power" coolers are considered: $Q_{\mathrm{C}}<10 \mathrm{~W}$ at 4 and $10 \mathrm{~K} ; Q_{\mathrm{C}}<100 \mathrm{~W}$ at 20 and $40 \mathrm{~K} ; Q_{\mathrm{C}}<200 \mathrm{~W}$ at $80 \mathrm{~K}$. The band in which $60 \%$ of the coolers fall statistically is indicated with horizontal dashes. In Fig. 2b, a comparison is made with the survey of Daunt and Goree and that of Smith. It can be concluded that over the years the cooler performance has not significantly improved, again except for the Stirling coolers and highfrequency pulse-tube coolers operating at $80 \mathrm{~K}$.

Another way of presenting the data in a historical perspective is to compare current data with old data in the format of the so-called "Strobridge plot". Strangely enough, Strobridge in his survey did not formulate a dependence of the efficiency on the operating temperature. Instead he focused on the other effect, that of the cooling power. He found an efficiency of a few $\%$ of Carnot in the $1 \mathrm{~W}$ range, increasing to roughly $30 \%$ in the megawatt-range independent of operating temperature. The Strobridge plot in Fig. 3 combines our data for $80 \mathrm{~K}$ coolers with the Strobridge data. The difference between the two categories of $80 \mathrm{~K}$ coolers is even more striking than in Fig. 1. Comparison with the Strobridge data should be focused on his square symbols. Again, the improvement in the performance of Stirling and Stirling-type pulse tubes has been most noticeable, with Stirling coolers being superior to pulse-tube coolers in the sub-1 W range. The improvement in the efficiency of 

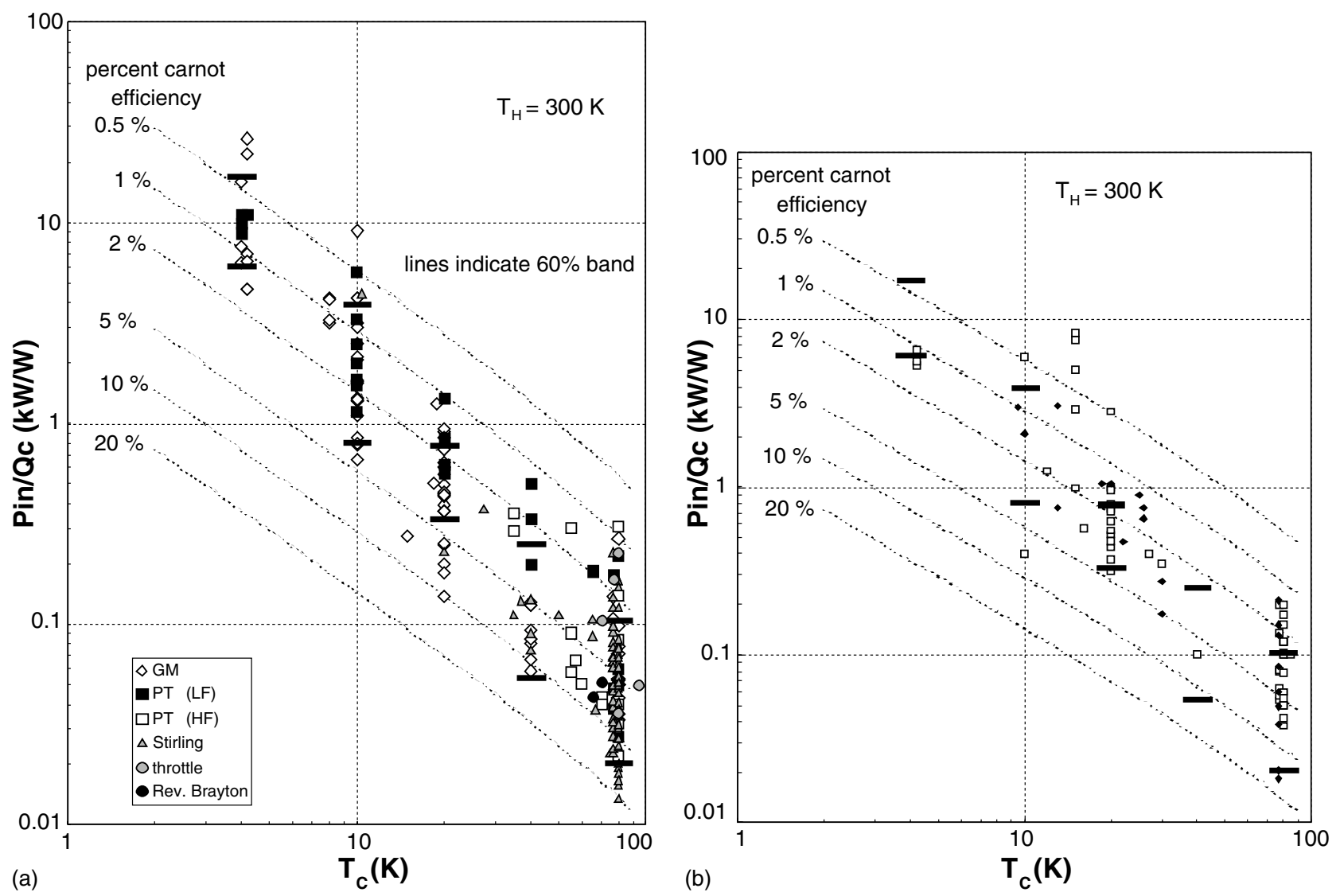

Fig. 2. (a) Specific power $P_{\text {in }} / Q_{\mathrm{C}}$ in $\mathrm{kW} / \mathrm{W}$ versus operating temperature for the different types of coolers. Heat sink is at $300 \mathrm{~K}$. Dashed lines correspond to a constant percent Carnot efficiency. The horizontal dashes indicate the $60 \%$ probability band for the coolers. (b) Specific power $P_{\text {in }} / Q_{\mathrm{C}}$ in $\mathrm{kW} / \mathrm{W}$ versus operating temperature. The $60 \%$ probability band of our database (horizontal stripes) compared to the database of Daunt and Goree (solid diamonds, 21 coolers, 1969, [6]) and to that of Smith et al. (open squares, 55 coolers, 1984, [10]). Dashed lines correspond to a constant percent Carnot efficiency.

$1 \mathrm{~W}$ coolers has been from about $1-2 \%$ of Carnot for the Strobridge data to about 5-10\% for the current generation of $1 \mathrm{~W} / 80 \mathrm{~K}$ cryocoolers.

\section{Mass and volume}

The database contains mass and volume data of 153 coolers. The relation between cooler mass and cooler volume is depicted in Fig. 4. For the complete database a linear fit can be made as included in the figure. This fit corresponds to a "cooler density" of $0.8 \mathrm{~kg} / \mathrm{l}$. The smaller Stirling coolers are more compact, however. Excluding the five heaviest Stirling coolers, the fit for Stirling coolers only is $1.12 \mathrm{~kg} / \mathrm{l}$.

Strobridge and also Smith et al. considered mass as a function of cooling power $Q_{\mathrm{C}}$. In doing so, however, one has to include the operating temperature as a parameter as well. This will be considered later on in this section. As an alternative, one can relate mass to input power, which is depicted in Fig. 5 for 170 coolers. The best linear fit intercepting the origin is mass $(\mathrm{kg})=0.0204 \times$
$P_{\text {in }}(\mathrm{W})$. This fit, however, deviates significantly from a large part of the data. The best fit for the complete set appeared to be mass $=0.0711 \times P_{\mathrm{in}}^{0.905}$, with mass in $\mathrm{kg}$ and $P_{\text {in }}$ in W. This fit is included in Fig. 5, as well as data from earlier surveys of Daunt and Goree, and of Smith et al. It appears that the general trend of cooler mass as a function of the input power has not significantly changed over time, except for the case of high-frequency pulse-tube coolers. These coolers are relatively heavy. One should note, however, that the efficiency of small Stirling coolers and high-frequency pulse tubes has increased by a factor of about 5 , as discussed in the above section. Therefore, per watt of cooling power at a given temperature less input power is required, and thus the cooler is lighter. This is also illustrated by Fig. 6, where the specific mass (i.e. mass per unit of cooling power) is plotted versus the operating temperature. Again included are the data of Daunt and Goree, and of Smith et al. Once more it can be concluded that the cooler mass has not significantly changed. Stirling coolers are relatively lighter, whereas high-frequency pulse-tube coolers are relatively heavier. 

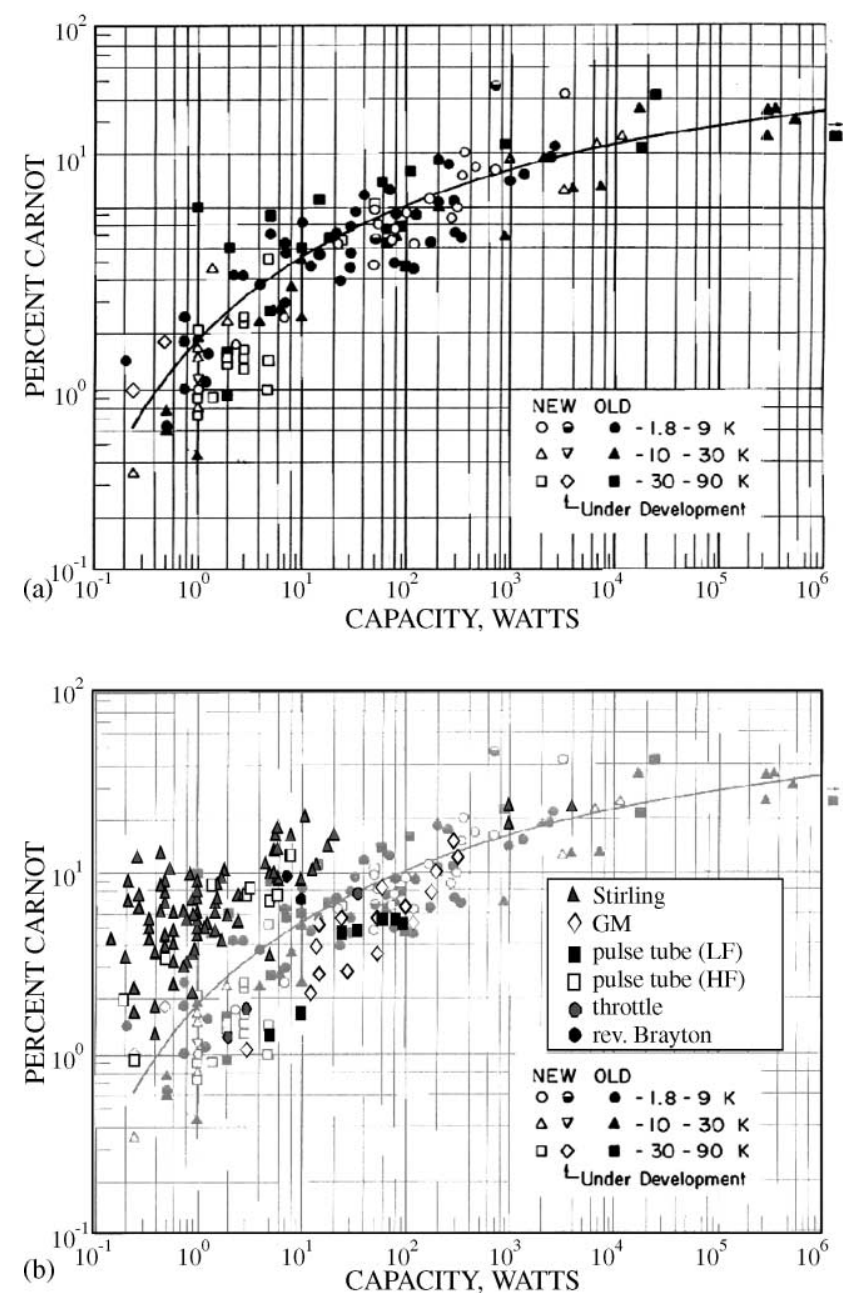

Fig. 3. (a) "Strobridge plot": percent Carnot effciency of various coolers in Strobridge's survey [8]. (b) Percent Carnot efficiency of $80 \mathrm{~K}$ coolers in 2002 CILTEC survey depicted in the Strobridge plot.

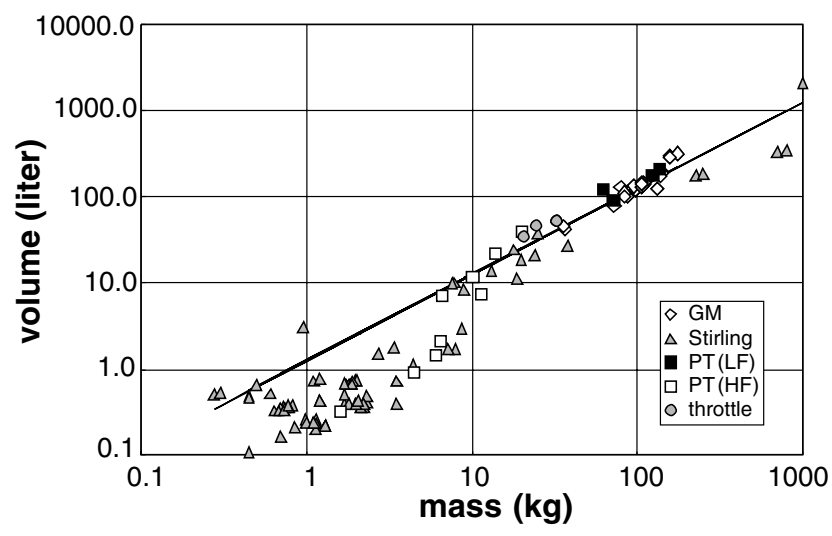

Fig. 4. Volume versus mass of 153 coolers. Solid line gives trend for this data: volume $($ liters $)=1.25 \times$ mass $(\mathrm{kg})$.

Relating mass to cooling power and operating temperature, we derived a fair fit between these three parameters:

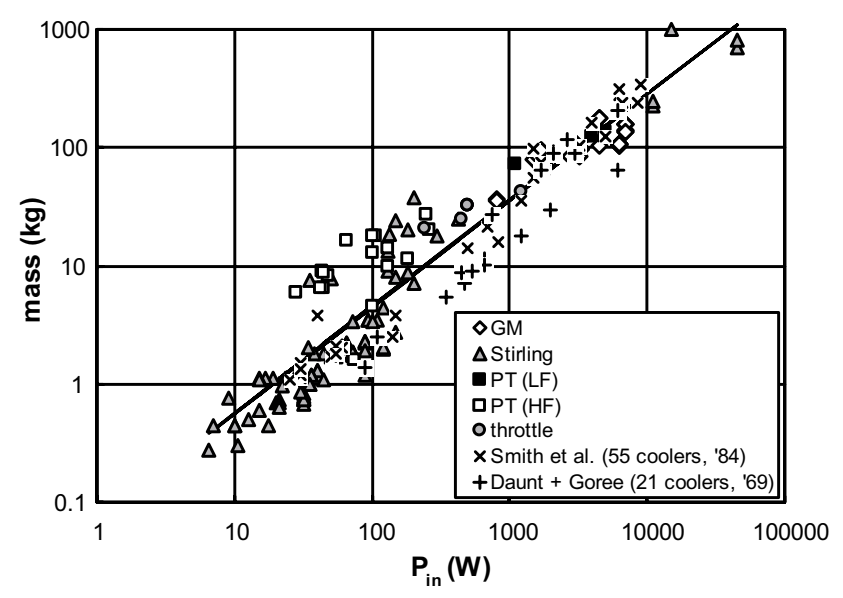

Fig. 5. Mass versus input power of 170 coolers. Solid line gives trend for this data: mass $=0.0711 \times P_{\text {in }}^{0.905}$. Data of Smith et al. [10] and of Daunt and Goree [6] are included.

mass $=\alpha(T) \times Q_{\mathrm{C}}^{\beta(T)}$

with

$\alpha(T)=157 \exp (-0.0533 T)$

$\beta(T)=0.009 T+0.1275$

(mass in $\mathrm{kg}, T$ in $\mathrm{K}, Q_{\mathrm{C}}$ in $\mathrm{W}$ ).

Mass versus cooling power for our database is depicted in Fig. 7, also including the fit given by Eq. (4).

\section{Cost}

The price of a cooler is determined by a number of factors. Besides political and economical factors, important parameters are the required performance (cooling power, operating temperature, COP), the number of coolers that is needed and the maturity of the technology. The relation between cost and performance is illustrated in Figs. 8 and 9, based on 83 coolers in the database. For input powers above $400 \mathrm{~W}$, a trend can be recognized as

$P_{\text {in }}>400 \mathrm{~W}: \quad \operatorname{cost}(\mathrm{k} \$)=10.78 \times P_{\text {in }}(\mathrm{kW})^{0.79}$

When considering cost versus cooling power, the operating temperature has to be included. Trend lines can be defined for 20,40 , and $80 \mathrm{~K}$, although the $80 \mathrm{~K}$ data contains a lot of scatter. These trends are included in Fig. 9 and are useful above a cooling power of about $2 \mathrm{~W}$ :

$$
\begin{aligned}
& T=20 \mathrm{~K}: \quad \operatorname{cost}(\mathrm{k} \$)=4.55 \times Q_{\mathrm{C}}(\mathrm{W})^{0.84} \\
Q_{\mathrm{C}}>2 \mathrm{~W}: & T=40 \mathrm{~K}: \quad \operatorname{cost}(\mathrm{k} \$)=3.93 \times Q_{\mathrm{C}}(\mathrm{W})^{0.74} \\
& T=80 \mathrm{~K}: \quad \operatorname{cost}(\mathrm{k} \$)=8.03 \times Q_{\mathrm{C}}(\mathrm{W})^{0.32}
\end{aligned}
$$




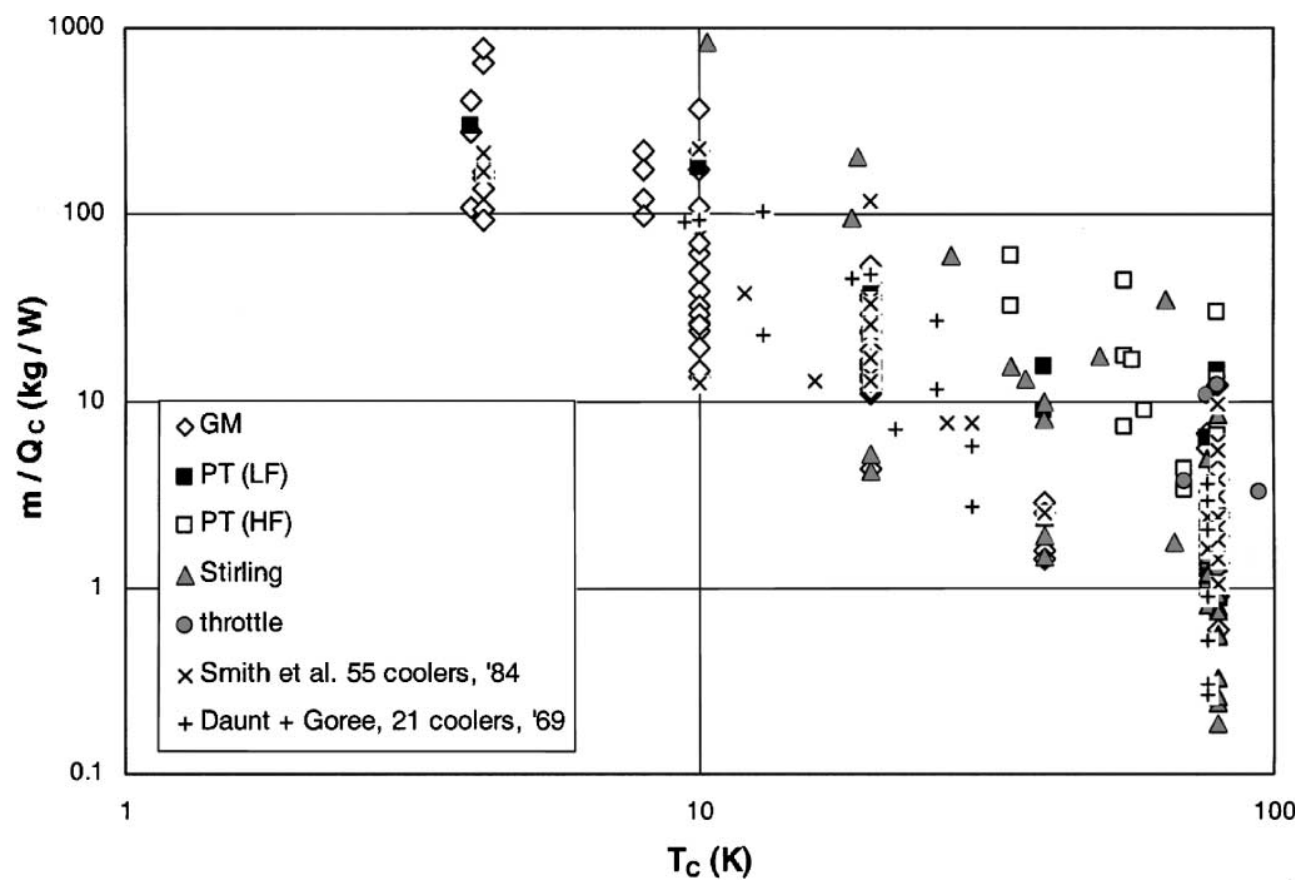

Fig. 6. Mass per unit of cooling power ("specific mass") versus operating temperature. Data of Smith et al. [10] and of Daunt and Goree [6] are included.

The cost of small-power coolers does not appear to depend on required cooling power or input power. One can imagine that the required lifetime also determines cost. This, however, appears not to be the case as illustrated by Fig. 10 for 63 coolers with partly overlapping data points.

An impression of the historical cost development can be obtained by comparing our data with that of Strobridge and of Daunt and Goree. In order to compare cooler price development with "normal" price level development, we took data from the U.S. Bureau of Labour Statistics on "industrial commodities". In 2001, this price level is a factor 2.8 above that of 1974 . Strobridge in his survey, updated in 1974, gave a relation similar to Eq. (5) as cost $(\mathrm{k} \$)=6 \times P_{\text {in }}(\mathrm{kW})^{0.7}$. At 1 and $100 \mathrm{~kW}$ his trend corresponds to 6 and $151 \mathrm{kS}$, respectively. Recent coolers according to Eq. (5) cost about 11 and $410 \mathrm{k} \$$ at those input levels, respectively. The cost increase, therefore, is a factor 1.8 at $1 \mathrm{~kW}$ and 2.7 at $100 \mathrm{~kW}$. Apparently, the powerful coolers (liquefiers) have followed the normal price development of industrial commodities. In contrast, more "modest" coolers have become significantly cheaper in a relative sense.

The price development of a specific type of cooler is a much more difficult issue. For that purpose, in surveys, performance data and cost data have to be available on individual coolers that are of the same type. We have to limit this discussion to $80 \mathrm{~K}$ Stirling coolers with a cooling power of about $2 \mathrm{~W}$. In the 1969 survey of Daunt and Goree, two coolers of that type are included.
In our database, we have 10 coolers of that class with partly overlapping data. The data are presented in Table 4. Taking into account an industrial-commodity price level development by a factor of 4 , it is obvious that these Stirling coolers have become much cheaper.

The usual way to display the effect of the quantity produced on the unit cost of an item is in a so-called learning curve. This is a double-log plot of cost per unit versus the quantity produced. The learning rate (LR) indicates how the cost is reduced when the production is doubled. For instance, an $80 \%$ learning rate means that the cost per unit drops to $80 \%$ if the quantity manufactured doubles. Learning curves of nine coolers are depicted in Fig. 11, with four trend lines included. Except for the Iwatani pulse-tube cooler, the learning rates are between $75 \%$ and $85 \%$. This learning-rate range seems to be valid for a wide variety of industrial products. Based on data of Nisenoff, the learning rates for T-Fords, 1-HP induction motors, and integrated circuits can be evaluated as $86 \%, 81 \%$, and $73 \%$, respectively [15-17].

In practice, the learning rate is not a smooth curve as suggested by Fig. 11. The major cost reductions follow revisions of cooler designs and improvements and automations of the manufacturing processes. Because of larger market expectations, a supplier may wish to increase the number of coolers produced. When this increase is large enough, it may be worthwhile to redesign the cooler and its manufacturing process. Such a redesign process can result in a dramatic cost reduction and a step in the learning curve. This was, for instance, 

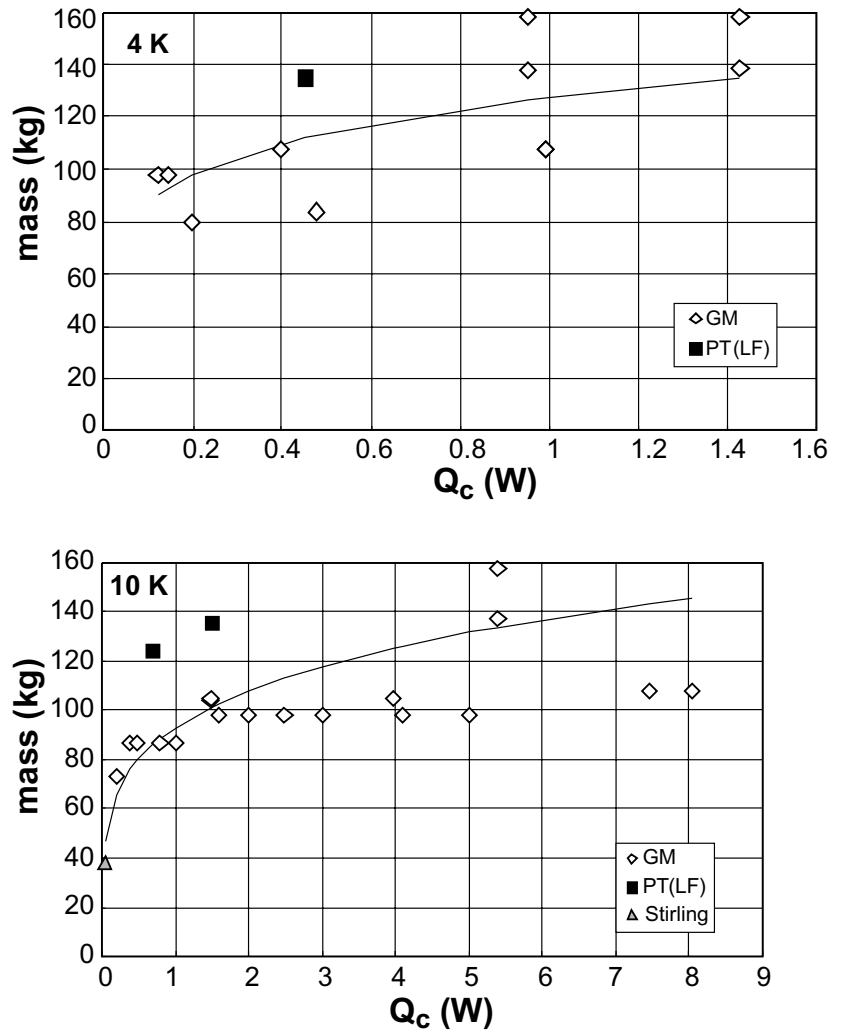

Fig. 7. Mass versus cooling power at five operating temperatures; the solid lines correspond to the fit given by Eq. (4).

demonstrated by the Sunpower redesign of the M77 Stirling cooler into the M87 Stirling cooler [20]. The M77 was designed for relatively small markets, e.g. aerospace applications. The first units were finished in 1992 and in 2000 a total of 71 units had been delivered. Because large markets were expected in cooling HTS telecom filters and in liquefying oxygen for home-based portable oxygen therapy, the M77 and its manufacturing process were redesigned with the goal of a manufacturing capacity of over 30,000 cryocoolers per year. Cooler redesign resulted in a $20 \%$ higher efficiency and a $23 \%$ lower mass. This contributed to a significantly lower price: the M77 currently costs $\$ 35,000$ per unit in small numbers, whereas the M87 is only $\$ 10,000$ in small numbers, dropping to a projected cost of $\$ 1500$ per unit for lots of 10,000 [21]. To arrive at this new design suitable for mass production, the number of weld/brazed joints, and the use of polymers and glue joints were each reduced by $50 \%$ or more [20]. Another example of a cooler and manufacturing redesign process was discussed in a paper of Superconductor Technologies Inc. (STI) at the 9th International Cryocooler Conference in 1996 [18].

These dramatic reductions in cost are only possible at large quantities. At small quantities, cost reduction is not that big. This is illustrated in Fig. 11 by the Sunpower M77 and M87 data as well as by the STI data; in
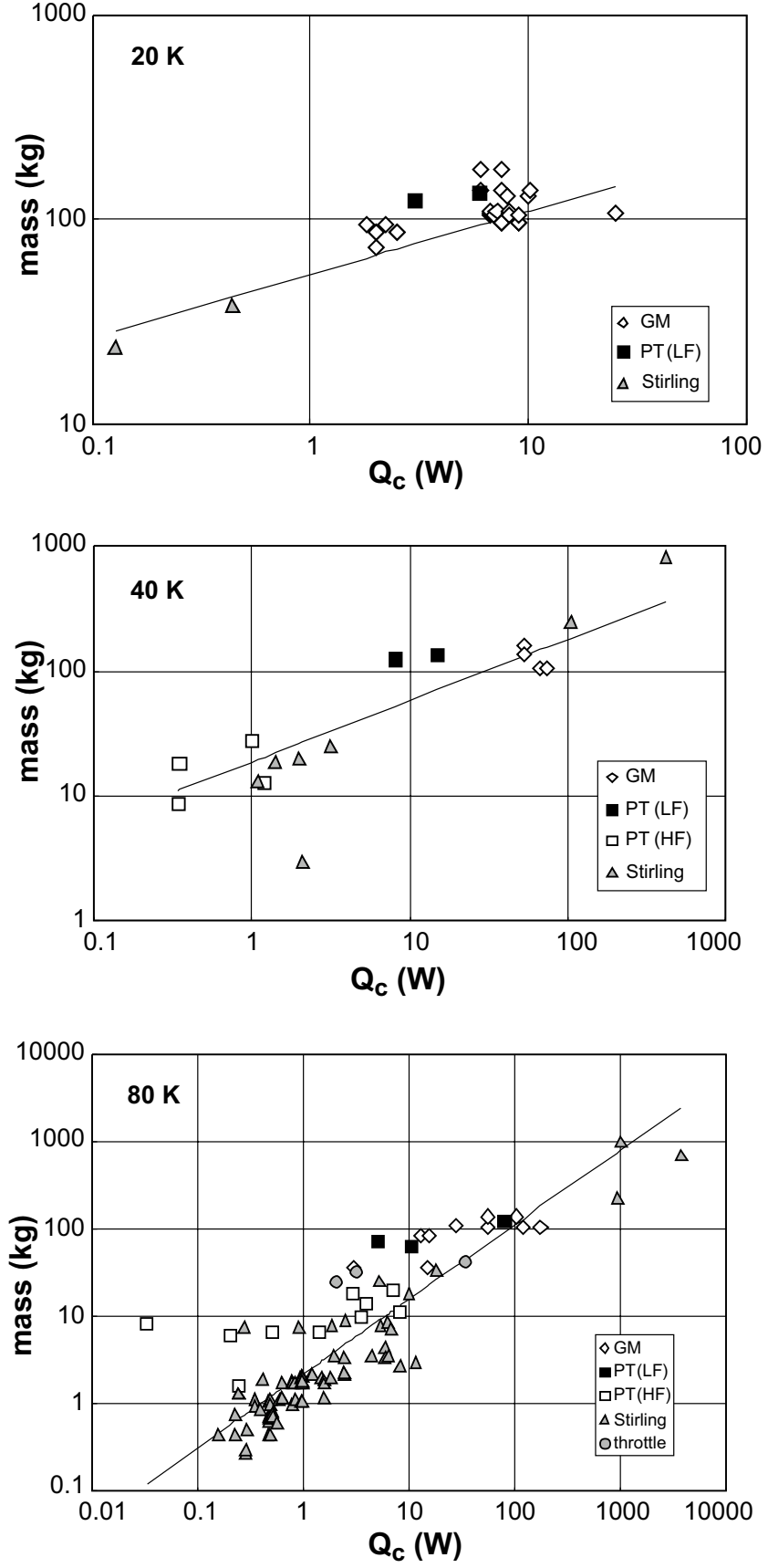

Fig. 7 (continued)

the quantity range $1-10$, the cost reduction following an increase in production is relatively small. In our database, cooler prices are included for single units and lots of 100. The reductions in cost per unit for 100 units as compared to a single unit are depicted in Fig. 12 for a dataset of 67 coolers. The average reduction to 0.64 of the single quantity price corresponds to a learning rate of only $93.5 \%$. Again, this reduction is quite modest. For comparison, a learning rate of $80 \%$ would imply a cost reduction to 0.23 of the unit price due to a production increase by a factor of 100 . 


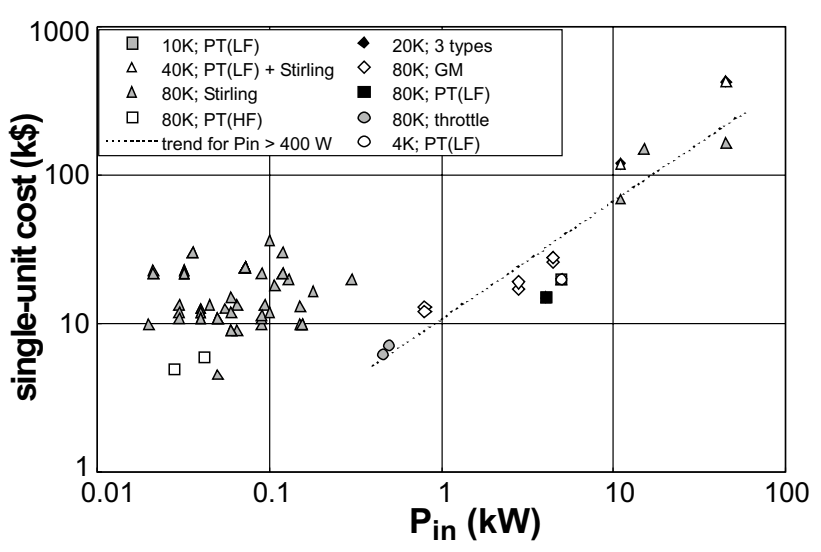

Fig. 8. Single-unit cost versus input power. Dotted line shows the trend for $P_{\text {in }}>400 \mathrm{~W}$ according to Eq. (5).

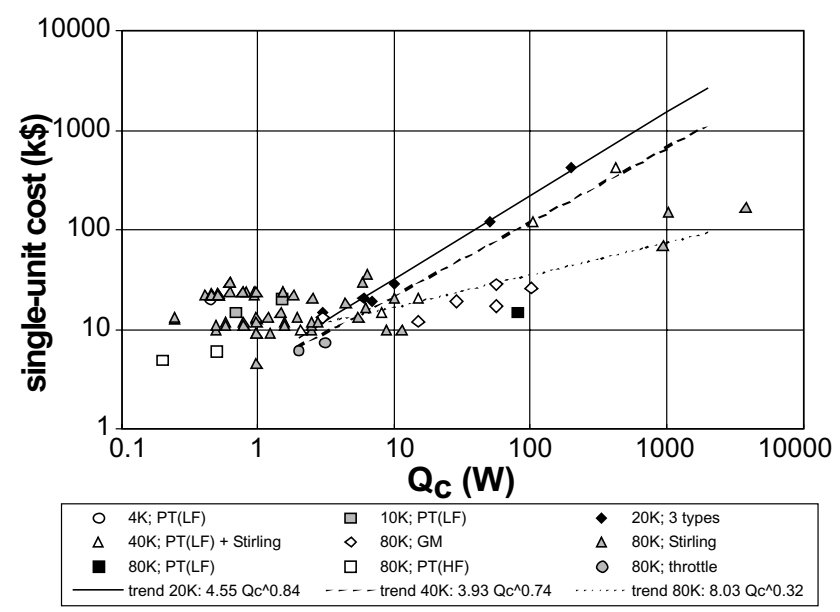

Fig. 9. Single-unit cost versus cooling power. Trend lines correspond to Eq. (6).

\section{Reliability and lifetime}

There is much confusion between the terms of "lifetime" and "reliability". Often the word "reliability" is

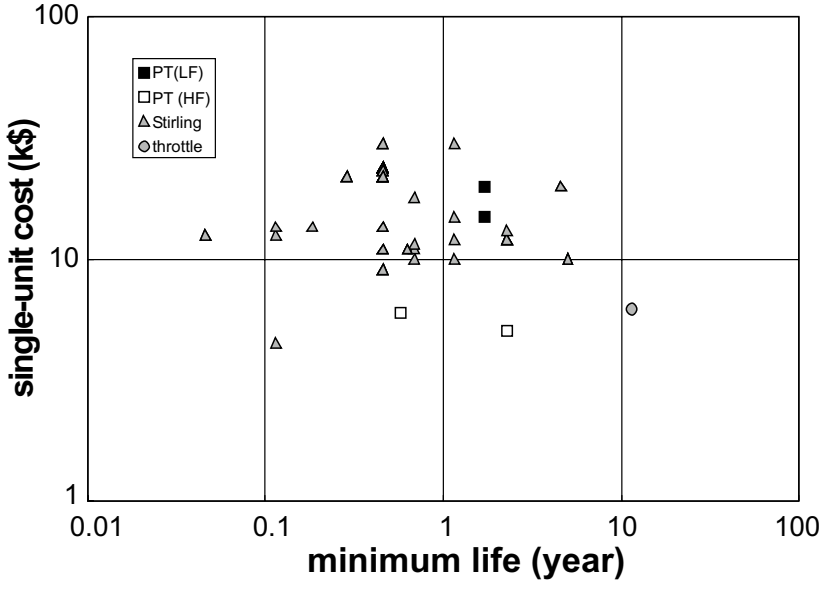

Fig. 10. Single-unit cost versus specified minimum life for 63 coolers. The low-frequency pulse-tube coolers are at $20 \mathrm{~K}$; the Stirling at $10 \mathrm{k} \$$ with a 5 -year life is at $40 \mathrm{~K}$; the other coolers are all at $80 \mathrm{~K}$.

used to imply that a cryocooler has a long operating "lifetime" but, in this use, it has no quantitative meaning. The term "lifetime" is frequently used by the supplier as the period of time that the cooler is guaranteed to operate according to the specifications. This lifetime does not mean that the cryocooler will not fail during the specified period of time; the cooler will have a finite probability of failing but, in general, the supplier is willing to replace or repair any defective cryocooler, at his expense. Reliability refers to that failure probability.

The rate at which devices under test fail is denoted by the failure rate $\lambda(t)$ : the number of failures per unit of time, normalized to the number of devices that is still operating at time $t$ [22]. A typical failure rate curve is given in Fig. 13, which due to its shape is often called the "bathtub curve". Early defects, causing "infant mortality", arise during manufacture and can be detected and removed from shipment before some predetermined number of operating hours. After shipment, most of the coolers will operate without problems and only a small number will fail because of random events (e.g. electrical

Table 4

2 W @ 80 K Stirling cooler performance and cost data of 1969 Daunt/Goree survey [6] compared to 2002 CILTEC survey

\begin{tabular}{|c|c|c|c|c|c|}
\hline Manufacturer & Type & $P_{\text {in }}(\mathrm{W})$ & $T_{\mathrm{C}}(\mathrm{K})$ & $Q_{\mathrm{C}}(\mathrm{W})$ & Single-unit cost (\$), price in 1969 \\
\hline \multicolumn{6}{|c|}{1969 survey of Daunt and Goree [6] } \\
\hline US Philips Corp. & Micro-Cryogem & 90 & 77 & 1.5 & 5250 \\
\hline Malaker Corp. & Cryomite & 108 & 77 & 2.8 & 9000 \\
\hline \multicolumn{6}{|c|}{2002 CILTEC survey } \\
\hline & & & & & Price in 2002 \\
\hline AIM-IR & SL $2000(6$ and 10$)$ & 94 & 80 & 2 & 13,500 \\
\hline AIM-IR & SL $150(\mathrm{~A}, \mathrm{~B}, \mathrm{C})$ & 90 & 80 & 2.5 & $10,000-11,500$ \\
\hline CMC Elec. Cinc. & $\mathrm{B} 1000$ & 60 & 80 & 1.5 & 15,000 \\
\hline Aisin Seiki & SPR02 & 130 & 80 & 2.5 & 20,000 \\
\hline Thales Cryogenics & LSF9188 & 60 & 80 & 1.6 & 12,000 \\
\hline Thales Cryogenics & UP7088, UP7098 & 50 & 80 & 1.6 & 11,000 \\
\hline
\end{tabular}




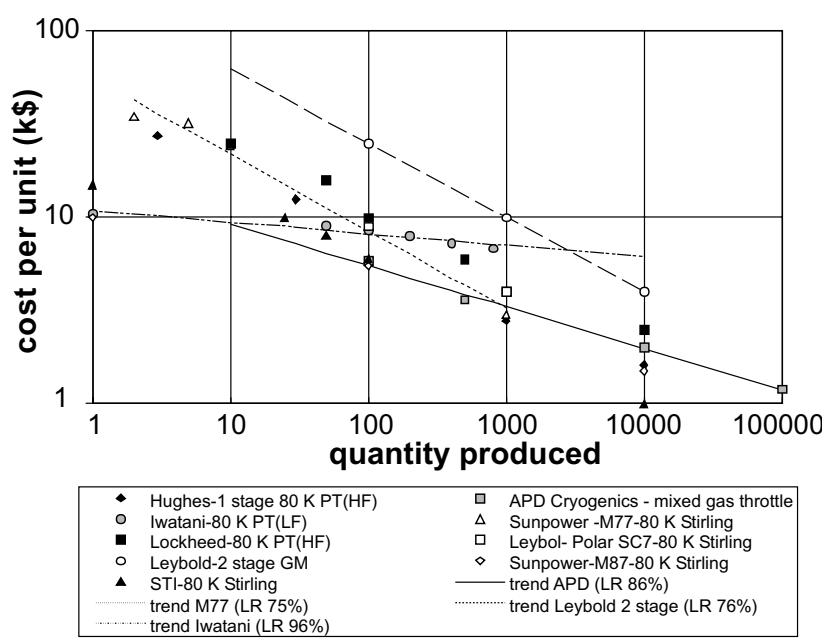

Fig. 11. Learning curves of nine coolers; STI data are from Ref. [18]; Sunpower M87 from 2002 CILTEC database; Leybold data Ref. [19]; other data Ref. [16].

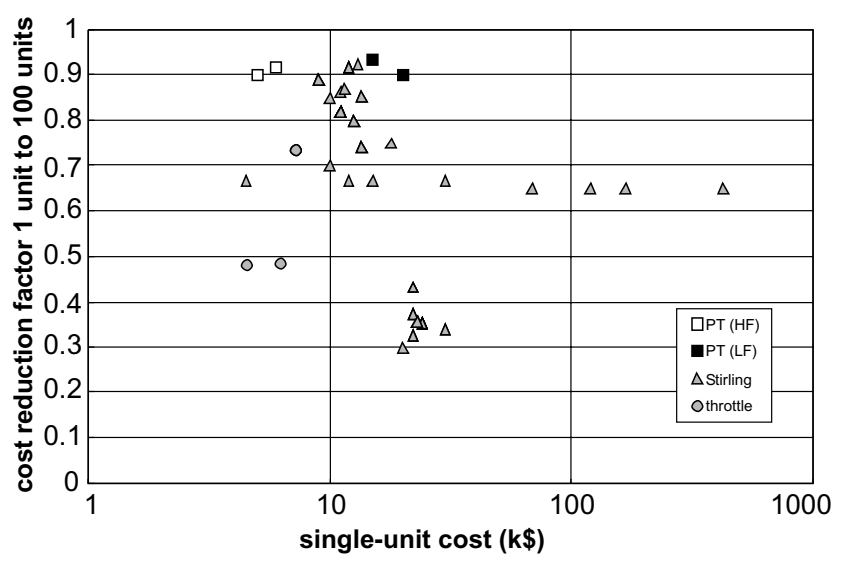

Fig. 12. Reduction in cost per unit for 100 units as compared to a single unit.

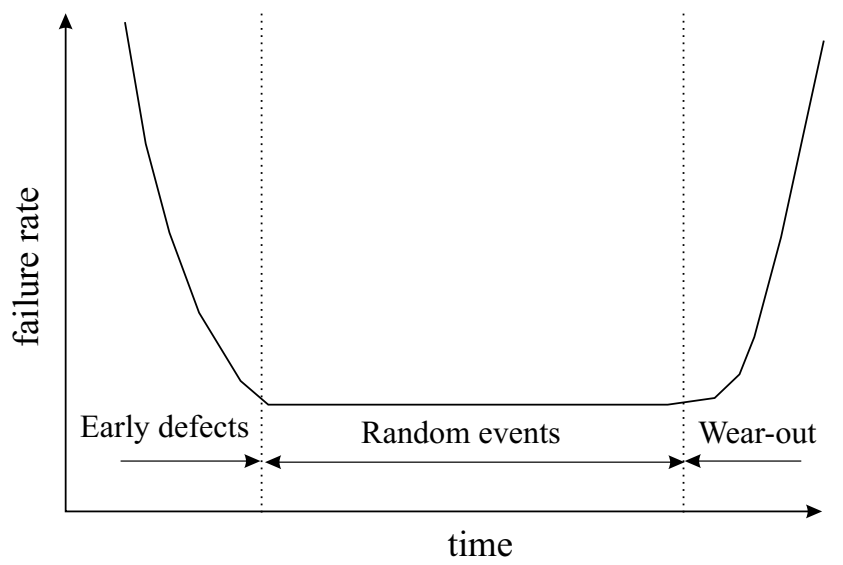

Fig. 13. Typical failure rate curve. damage). We assume these events to occur randomly over all period, and as a result the failure rate is constant in this period. At some point in time, wear-out mechanisms will occur and become more and more important as time evolves. In contrast to random events, wear-out will affect all coolers, e.g. wear-out of seals or leakage of helium. The pace at which these mechanisms work may vary from cooler to cooler, but all coolers suffer from this "wear-out". The end-of-life occurs when wear-out starts to dominate over the random defects. Usually at that point, the failure rate rapidly increases. Thus lifetime is related to the length of the random-event period, whereas the reliability is related to the failure rate in that period. It may be illustrative to note that a liquid-helium bath has a limited lifetime but is extremely reliable.

In failure and reliability analysis, a reliability function $R(t)$ is used to indicate the probability that a device will perform its intended function for at least a time $t$ [22]. In a life test experiment, it is the number of devices that is still operating at time $t$ relative to the initial number. In the random-event regime, since $\lambda$ is constant, the reliability function decays exponentially in time:

Random events: $\quad R(t)=\exp (-\lambda t)$

In general, a mean-time-to-failure (MTTF) can be evaluated by considering the number of failures at time $t$ in the time interval $\mathrm{d} t$. This number of failures is equal to $\lambda(t) R(t) \mathrm{d} t$, and has a time-to-failure $t$. Obviously, the MTTF follows as

$\operatorname{MTTF}=\int_{0}^{\infty} t \lambda(t) R(t) \mathrm{d} t$

Here, $t=0$ is at the beginning of operation of the cooler by the user, that is, after the cooler has survived the "burn-in" during the "infant mortality" phase, and has been shipped to the user. Then, in the first period of operation, $\lambda$ is constant, and the MTTF in this regime resulting from Eqs. (7) and (8) is simply equal to $1 / \lambda$. For coolers under operation, this MTTF directly translates into the cumulative number of operating hours divided by the number of failures that have occurred:

Random events: $\quad$ MTTF $=1 / \lambda$

$$
=\frac{\text { cumulative } \# \text { hours }}{\# \text { failures }}
$$

Two important remarks have to be made at this point. Firstly, this MTTF should not at all be interpreted as "the lifetime". As discussed above, lifetime is determined by wear-out mechanisms and not by the random defects. It is far better to relate the MTTF of Eq. (9) to reliability; the chance that a cooler fails before its specified end-of-life is given as the lifetime divided by that MTTF. For example, in order to establish a cooler reliability of $95 \%$ (i.e. $5 \%$ failure) for a 5 -year lifetime, an MTTF of 100 years(!) has to be realized in 
the random-events phase. Secondly, the estimates that are made may pertain only to the reliability for a time period less than or of the order of the test duration, and reliability estimates cannot be given for other time periods. For example, a test with 10,000 coolers operated for 1 year with 10 failures yields the same MTTF as a run with 1000 coolers operated for 10 years and 10 failures. But clearly the latter test MTTF is more meaningful since it gives a reliability estimate valid for 10 years instead of only 1 .

The best statistics currently available for a commercial cryocooler is from STI [23]. Of the present Stirling cooler type H3.5 used for cooling HTS filters, the first units started operation in September 1999. In March 2002, a total of 1175 coolers had accumulated $10,719,272 \mathrm{~h}$ of operation. A total of 98 of them had been operating for more than 17,250 h. Since September 1999, a total of 13 coolers had failed, yielding an MTTF of 824,559 h (i.e. 94 years!). The targeted life of the cooler is $60,000 \mathrm{~h}$ [24], implying a reliability of about $93 \%$. Now the problem is that the coolers at STI were placed into operation on a more or less continuing basis with time, and only half of the coolers had been operating for more than 1 year. So, it is risky to use the reliability estimates for a period longer than about a year, let alone for the full period of $60,000 \mathrm{~h}$, about 7 years. After all, it is still to be seen whether the failure rate remains constant in time and does not slowly increase towards the specified end-of-life. Furthermore, the presented data do not give information on how realistic the lifetime of $60,000 \mathrm{~h}$ is, at least not beyond a year or so.

In the wear-out regime, $\lambda(t)$ rapidly increases with time. An expression that is often used in this case for the reliability function is the Weibull law [22]:

Weibull: $\quad R(t)=\exp \left[\frac{-(t-\gamma)^{\beta}}{\alpha}\right]$

Here, $\gamma$ is the operating time before which no failures occur (usually $\gamma=0$, assuming that the probability of failure is already above 0 immediately after starting); $\alpha$ is a scale parameter; and $\beta$ is a shape parameter. If $\beta=1$, Eq. (10) reduces to the exponential distribution with $\lambda$ constant (i.e. the random-events regime). In the wearout regime, $\beta$ is significantly larger than 1 . The three parameters in Eq. (10) can be evaluated from earlier lifetime test results. Unfortunately, it is difficult to obtain adequately accurate parameters and, therefore, the Weibull law is of limited practical use, e.g., Refs. [24,25]. As a result, the specified lifetime is usually based on targets rather than on real evaluations.

The lifetime of cryocoolers has been improved significantly over the last 5 years or so, due to improvements in the compressor and in the cold head (the gas-expansion unit). Concerning the latter, main attention has been on eliminating the moving parts in the cold. Typ- ical examples are the pulse-tube refrigerator and developments in Joule-Thomson cooling. With respect to the compressor, the key issue was the rubbing contact between the piston and the cylinder in oil-free compressors for Stirling-type coolers. Wear out of the rubbing seals that were used was the limiting factor in compressor lifetime. Now, these rubbing contacts can be eliminated by using flexure bearings that support the piston and the displacer inside their respective cylinders without any contact. By very accurate machining, the gap between piston and cylinder can be reduced to a few $\mu \mathrm{m}$. The flow impedance of this clearance gap is so high that it acts as a dynamic seal for the helium gas. Because of the extremely narrow gaps, the bearings that support the pistons have to be stiff in the radial direction and weak in the axial direction. This is realized with so-called flexure bearings. The lifetime of these compressors can exceed 50,000 h, whereas standard Stirling compressors had a specified life of less than $10,000 \mathrm{~h}$, and more typically $5000 \mathrm{~h}$. The work on these long-life compressors was pioneered by Davey of the University of Oxford in the early and mid 80s [26,27]. These were developed especially for space applications with extremely long life (10 year) in single units and, therefore, at high cost. Nowadays, these compressors are under development for highly reliable long-life pulse-tube coolers and are also available in some commercial coolers e.g., Refs. $[28,29]$. As an alternative to flexure bearings, a gas bearing fed by a high-pressure reservoir in the piston can also be used to prevent rubbing contact [20,24].

A further improvement with respect to lifetime is to apply moving-magnet technology. This has several advantages over moving-coil linear motors that have been used in most linear compressors [18,28,29]. First of all, the coils, known to be a possible source for gas contamination, can be placed outside the hermetically sealed compressor housing containing the working gas. Avoiding any synthetic material inside the cooler reduces the risk of gas contamination during the life of the cooler. The fact that the coils can be placed outside the hermetically sealed compressor also means that no wire feedthroughs are required. In this way, risks of feedthrough leakage due to extreme temperature cycles or mechanical shocks are no longer present. Finally, the absence of moving coils in the compressor design also means that flying leads to supply power to the coils are no longer needed. These flying leads have an obvious risk of breaking during their 50 or $60 \mathrm{~Hz}$ operation for many, many hours (i.e., more than 4 million cycles per day!).

At this point, it is good to note that often a trade-off has to be made between manufacturing cost and reliability or lifetime. Often other aspects, such as cooler interference, may play a role as well. This trade-off is eminent in the discussion of "moving-coil or movingmagnet?". A moving-magnet compressor, on the one 


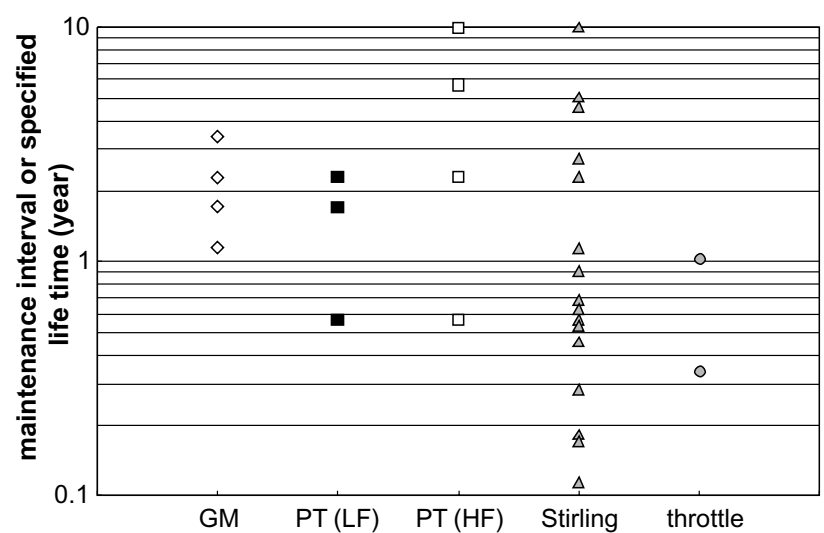

Fig. 14. Distributions of maintenance intervals or specified lifetimes per cooler type.

hand, has the above-mentioned advantages on reliability. On the other hand, it is slightly less efficient and generally leads to higher (low-frequency) electromagnetic interference [18,29]. Especially the efficiency drawback caused STI to adapt their compressor design from moving-magnet [18] to moving-coil [24].

In the 2002 CILTEC cryocooler database, data is included on maintenance intervals and specified lifetimes without maintenance. This data is summarized in Fig. 14 for 149 coolers (with lots of overlaps). The statistics for the different distributions are given in Table 5. Two Stirling coolers with lifetimes of only $400 \mathrm{~h}$ were included in the statistics but not in Fig. 14. Obviously, large numbers of coolers are available nowadays with operating times far over 1 year, with special efforts and results in high-frequency pulse-tube and Stirling coolers.

\section{Conclusion}

A cryocooler survey has been performed. Data was gathered from publicly available sources and suppliers were approached with the data on their coolers, and they were asked to update this. The database is available as a spreadsheet and can be obtained free of charge by contacting CILTEC [14]. We welcome comments about the present survey and database and would welcome data on new coolers and further updates.

A trend study was performed in this survey and the results are summarized in Fig. 15a-c; Fig. 15a depicts
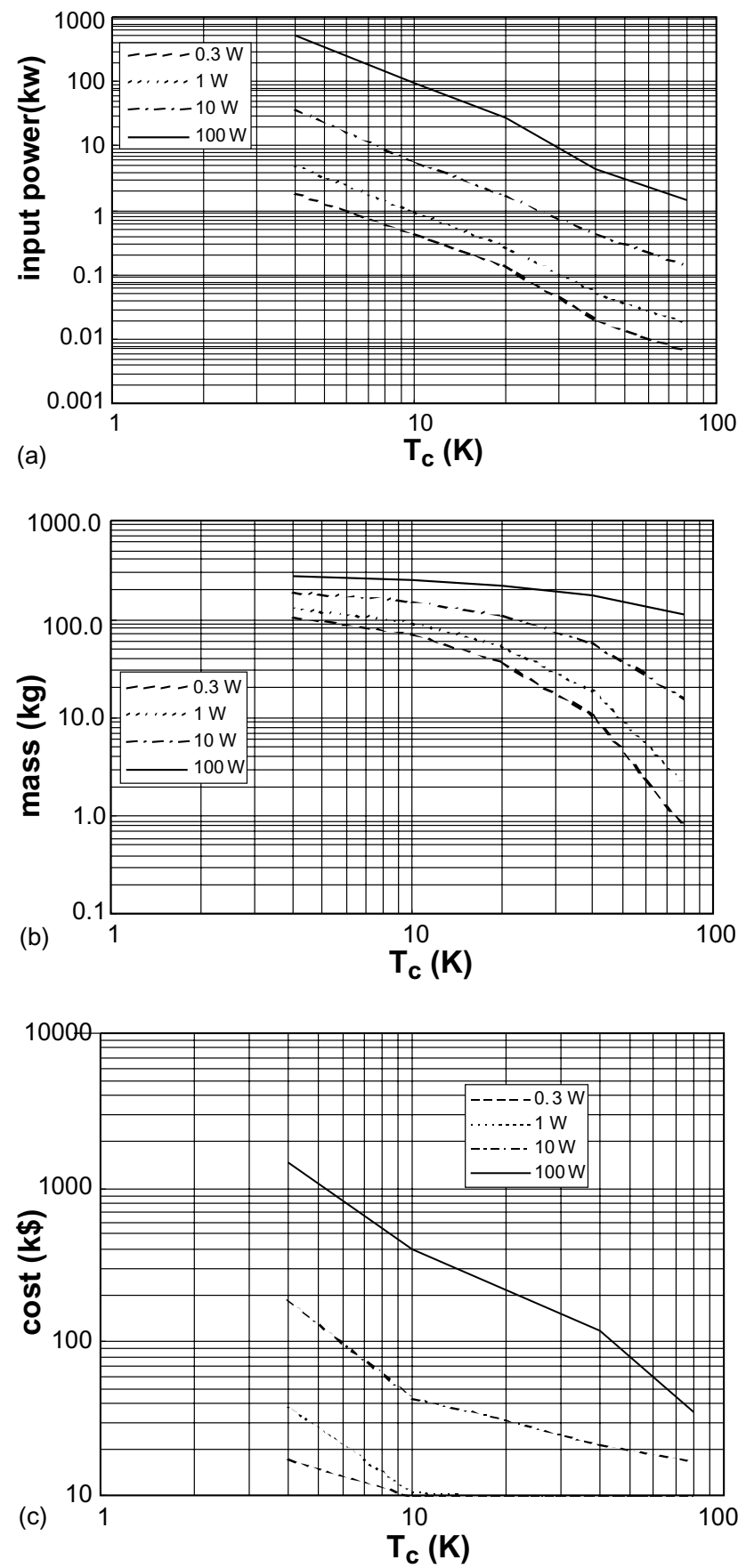

Fig. 15. (a) Estimated input power versus operating temperature with cooling power as the parameter. (b) Estimated cooler mass versus operating temperature with cooling power as the parameter. (c) Estimated cooler cost versus operating temperature with cooling power as the parameter.

Table 5

Statistics in distributions of maintenance intervals or specified lifetimes (numbers are rounded)

\begin{tabular}{lrrrrr}
\hline & GM & PT (LF) & PT (HF) & Stirling & Throttle \\
\hline Number of coolers & 47 & 11 & 7 & 81 & 3 \\
Average & 14,400 & 15,900 & 44,700 & 14,200 & 7000 \\
Standard deviation & 7000 & 5800 & 26,300 & 22,800 & 3500 \\
Statistical percentage $>1$ year & $79 \%$ & $89 \%$ & $91 \%$ & $59 \%$ & $31 \%$ \\
\hline
\end{tabular}


the input power versus the operating temperature, with the cooling power as a parameter varying from 0.3 to $100 \mathrm{~W}$. This figure is based on currently achievable efficiencies as depicted in Fig. 1. The cooler mass is plotted against operating temperature in Fig. 15b, based on Eq. (4). Finally, the cooler cost as a function of temperature and cooling power is given in Fig. 15c. This plot is based on the Eqs. (5) and (6), with $10 \mathrm{k} \$$ taken as a lower limit. All graphs should be used for useful estimate purposes only.

\section{Acknowledgements}

The authors wish to thank Marty Nisenoff for supplying cooler data and other relevant information, but most of all for his contribution in the discussions on the database, the survey, and the manuscript, always in a very enthusiastic and stimulating manner. Also, we want to thank the cooler manufacturers as listed in Table 2 for their contributions and feedback. The authors are financially supported by the MESA+ Research Institute of the University of Twente.

\section{References}

[1] Gifford WE, Longsworth RC. Pulse-tube refrigeration, ASME paper no. 63-WA-290. In: Winter Annual Meeting of the American Society of Mechanical Engineers, Philadelphia, PA, 17-22 November 1963.

[2] Mikulin EI, Tarasov AA, Shkrebyonock MP. Low-temperature expansion pulse tubes. In: Advances in cryogenic engineering, vol. 29. 1984. p. 629.

[3] Ter Brake HJM. Cryogenic systems for superconducting devices. In: Weinstock $\mathrm{H}$, editor. Applications of superconductivity. Dordrecht: Kluwer Academic Publishers; 2000. p. 561-639.

[4] Walker G. Cryocoolers, part 1: Fundamentals, part 2: Applications. New York: Plenum Press; 1983.

[5] Ross Jr RG, editor. Series of cryocoolers, vols. 8-11. New York: Plenum Press; 1995-2001.

[6] Daunt JG, Goree WS. Miniature cryogenic refrigerators. Report Office of Naval Research, July 1969, contracts Nonr-263(70) and N00014-67-C-0393.

[7] Strobridge TR. Refrigeration for superconducting and cryogenic systems. IEEE Trans Nucl Sci 1969;NS-16(3, part 1):1104 8.

[8] Strobridge TR. Cryogenic refrigerators-An updated survey. National Bureau of Standards Technical Note 655 (Supt. Documents, U.S. Govt. Printing Off.), 1974.

[9] Crawford AH. Specifications of cryogenic refrigerators. Cryogenics 1970;10:28-37.

[10] Smith Jr JL, Robinson Jr GY, Iwasa Y. Survey of the state-of-theart of miniature cryocoolers for superconducting devices. NRL Memorandum Report 5490, Naval Research Laboratory, Washington DC, 1984.

[11] Glaister DS, Donabedian M, Curran DGT, Davis T. An overview of the performance and maturity of long life cryocoolers for space applications. In: Ross Jr RG, editor. Cryocoolers, vol. 10. New York: Plenum Press; 1999. p. 1-20.

[12] Naval Research Laboratory "Cryo Cooler Database Version 1.0, April 1999", Prepared by Nichols Research, Albuquerque, NM, USA.

[13] Bruning JL, Torrison R, Radebaugh R, Nisenoff M. Survey of cryocoolers for electronic applications (C-SEA). In: Ross Jr RG, editor. Cryocoolers, vol. 10. New York: Plenum Press; 1999. p. 829-35.

[14] CILTEC, Center for Interfacing Low-Temperature Electronics and Coolers; www.ciltec.org. E-mail: info@ciltec.org.

[15] Abernathy WJ, Wayne K. Limits of the learning curve. Harvard Business Rev 1974;52:109-19.

[16] Nisenoff M. Personal communication, April 2002. Data also presented at Cryoelect. Workshop, February 1999.

[17] Boston Consulting Group. Perspective on experience. Ann Arbor, MI: University Microfilm International; 1979.

[18] Loung V, O'Baid A, Harper S. Path to low cost and high reliability Stirling coolers. In: Ross Jr RG, editor. Cryocoolers, vol. 9. New York: Plenum Press; 1997. p. 97-108.

[19] Häfner HU. Kryorefrigeratoren, eine wichtige Hilfskomponente für Supraleiteranwendungen Status und Ausblick, at "Fachtagung Supraleitung, eine Komponente zukünftiger Energieversorgung?". VWEW-Energieverlag, February 2001

[20] Unger RZ, Wiseman RB, Hummon MR. The advent of low cost cryocoolers. In: Ross Jr RG, editor. Cryocoolers, vol. 11. New York: Plenum Press; 2001. p. 79-86.

[21] Crawford J (Sunpower). Personal communication, April 2002. Data included in the 2002 CILTEC Cryocooler Database.

[22] Green AE, Bourne AJ. Reliability technology. 2nd ed London: John Wiley \& Sons; 1977;

Nash FR. Estimating device reliability: assessment of credibility. Dordrecht: Kluwer Academic Publishers; 1993;

Martz HF, Waller RA. Bayesian reliability analysis. New York: John Wiley \& Sons; 1982;

In addition, report downloadable from: www.mitsubishichips.com/data/reliab.

[23] Kunimoto W. Performance \& reliability data for production free piston Stirling cryocooler. In: Workshop on Military \& Commercial Applications for Low-Cost Cryocoolers, M-Calc 3, 25-26 October 2001, updated in personal communication, April 2002.

[24] Hanes M. Performance and reliability improvements in a low-cost Stirling cycle cryocooler. In: Ross Jr RG, editor. Cryocoolers, vol. 11. New York: Plenum Press; 2001. p. 87-95.

[25] Cauquil M, Martin JY, Bruins P, Benschop T. MTTF prediction in design phase on THALES CRYOGENICS integral coolers. In: 12th International Cryocooler Conference, June 2002; to be published in Ross Jr RG, editor. Cryocoolers, vol. 12. New York: Plenum Press; 2003.

[26] Jones BG. Development for space use of BAe's improved singlestage Stirling cycle cooler for applications in the range 50-80 K. In: Ross Jr RG, editor. Cryocoolers, vol. 8. New York: Plenum Press; 1995. p. 1-11.

[27] Davey G. Review of the Oxford cryocooler. In: Fast RW, editor. Advances in cryogenic engineering, 35. 1990. p. 1423-30.

[28] Meijers M, Benschop AAJ, Mullié JC. High reliability coolers under development at Signaal-USFA. In: Ross Jr RG, editor. Cryocoolers, vol. 11. New York: Plenum Press; 2001. p. $111-8$.

[29] Benschop T. Flexure bearing cryocoolers at Thales Cryogenics. In: Workshop on Military \& Commercial Applications for Low-Cost Cryocoolers, M-Calc 3, 25-26 October 2001. 